\title{
A CASE REPORT OF AN ENORMOUS PROLAPSED PEDUNCULATED SUBMUCOUS MYOMA
}

\author{
Kovachev E. \\ Department of Obstetrics and Gynecology, \\ Prof. Paraskev Stoyanov Medical University of Varna
}

Reviewed by: prof. St. Ivanov

\begin{abstract}
We report the case of a patient with a large spontaneous prolapse of a pedunculated uterine submucosal leiomyoma expelled from the introitus. After the vaginal myomectomy, we performed a total abdominal hysterectomy, because of the enormous size of the myomatous uterus. The final histopathological report revealed a benign submucous leiomyoma and the postoperative recovery was quick without any complications.
\end{abstract}

Key words: submucous myoma, pedunculated, uterus

\section{INTRODUCTION}

Uterine fibromyomas are the most common tumours of the female genital tract and are classified as submucosal, intramural, or subserosal. Myomas are usually associated with abnormal vaginal bleeding, lower abdominal pain, threatened abortion, recurrent miscarriage, intrauterine growth retardation, abruptio placentae, preterm labor, infertility (1). Some of the submucous myomas may be pedunculated and eventually can protrude through the cervical canal and into the vagina $(4,7)$. Even very large myomas can prolapse into the vagina and outside (8). After that, the myoma usually becomes necrotic and sometimes infected (2).

Myomectomy for submucous leiomyomas can be accomplished by open, laparoscopic, hysteroscopic, and vaginal approaches $(5,9)$.

\section{Case presentation}

A 49-year-old nulliparous woman was hospitalized in the gynecological department with abnormal vaginal bleeding. Pelvic examination revealed the presence of a large tumour mass measuring $38 \mathrm{~cm}$ in diameter and prolapsed from the vagina (figure 1). The ultrasound examination demonstrated several fibroids as focal masses with a heterogeneous texture and determined one more submucosal and two intramural myomas. The biggest intramural fibroids measured $85.4 \times 84.7 \mathrm{~mm}$ and are visualized on figure 2 . Laboratory tests showed low haemoglobin level of $72 \mathrm{~g} /$; hematocrit $0.26 \mathrm{~L} / \mathrm{L} ; \mathrm{MCV}-70.6 \mathrm{FL} ; \mathrm{MCH}$ - 20.6 pg; RDW - 30.2\%; WBC - $7.3 \mathrm{G} / \mathrm{L}$.

Address for correspondence:

E. Kovachev, SBAGAL -Varna, Dept. of Obstetrics and Gynecology; Medical Centre of Assisted Reproduction "Varna" Ltd,

150, Tsar Osvoboditel Blvd, 9000 Varna - Bulgaria

e-mail: kovachev_md@abv.bg
With these clinical findings, we inrpreted the mass as a prolapsed pedunculated submucous myoma. After the intensive reanimation a vaginal myomectomy was planned.

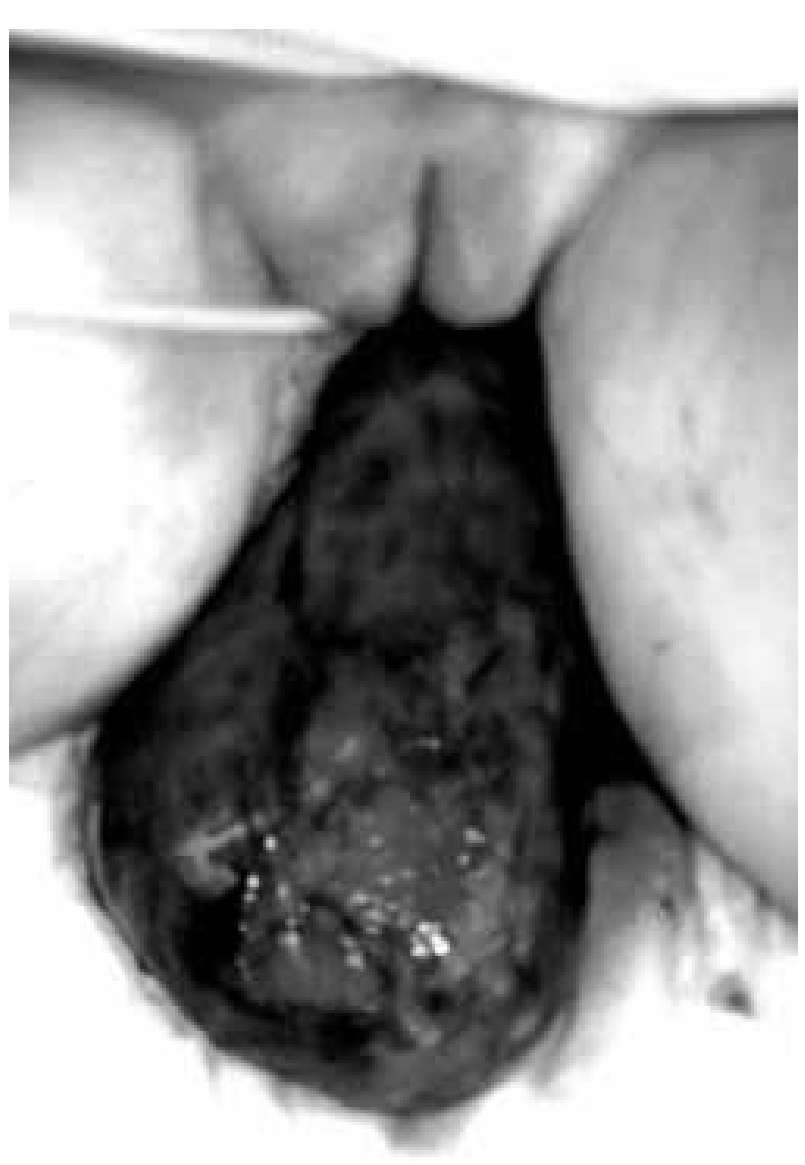

Fig. 1. A view of a prolapsed pedunculated submucous myoma. 
The fibroid was clamped and twisted around its pedicle and the stump was ligated under direct vision. When bleeding from the pedicle stump persisted, electrocoagulation was performed. A vaginal myomectomy followed by laparotomy with Pfannenstiel incision and total abdominal hysterectomy was performed (figure 3 ). The postoperative period was uneventful and the patient was discharged from the hospital six days after the surgery.

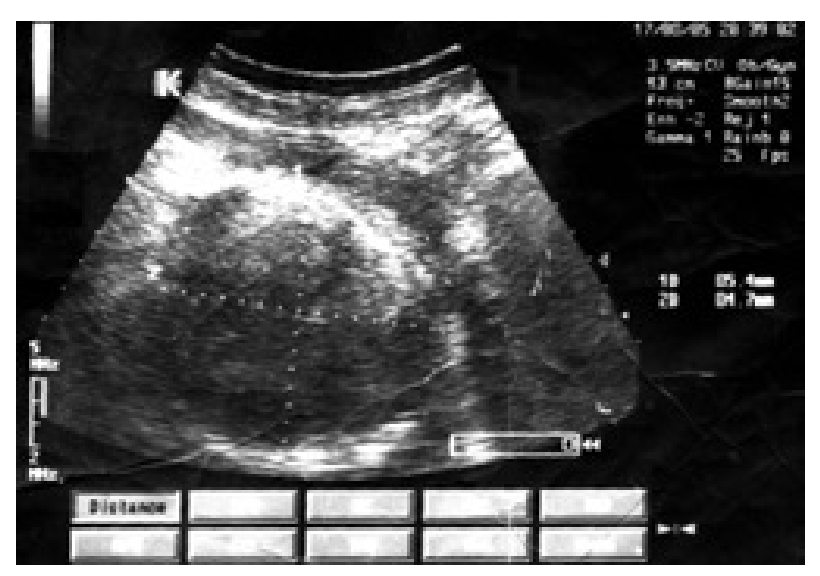

Fig. 2. Ultrasound image of an intramural fibroid of the patient.

The final histopathological report revealed a benign submucous pedunculated leiomyoma and myomatous uterus. Venous thrombosis and congestion with interstitial hemorrhage are responsible for the color of a leiomyoma undergoing red (carneous) degeneration.

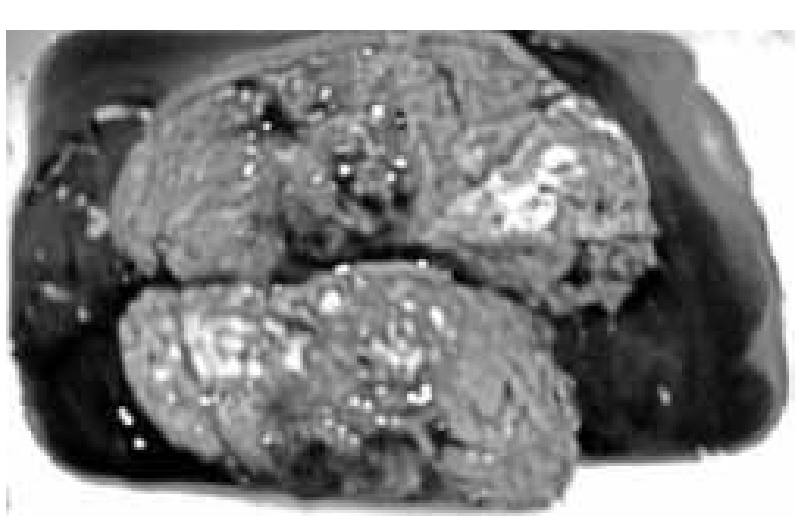

Fig. 3. Submucous pedunculated leiomyoma and myomatous uterus with carneous (red) degeneration.

\section{DISCUSSION}

On the first clinical step, after the gynecological and ultrasound examination, we rejected uterine inversion, which is possible after sudden expulsion of the large tumour (3). The main symptoms of non-puerperal uterine inversions are anaemia caused by irregular vaginal bleeding, vaginal discharge, lower abdominal pain, a protruding mass in the vagina, and in some cases obstruction of the urethra $(3,6)$. Our patient had not visited routine gynecological and ultrasound examinations and the reason was the enormous tumour size. She was hospitalized after a sudden prolapse of the myoma following physical activities.

\section{CONCLUSION}

We report a case of a prolapsed pedunculated submucous myoma with enormous size (1800 g), life-threatening vaginal bleeding and anemia.

Imaging modalities cannot clearly distinguish between the benign uterine leiomyoma and the malignant leiomyosarcoma and in some cases a biopsy is required. Vaginal myomectomy can be chosen as a method of treatment for prolapsed pedunculated submucous myomas. In other cases, when the myoma is not very large a hysteroscopic resection is planned.

\section{REFERENCES}

1. Decherney A, Nathan L. Current Obstetric\& Gynecologic Diagnosis\&Treatment, Ninth Edition 2003, Lange Medical Books/McGraw-Hill, 693-699.

2. Demirci F, Somunkiran A, Safak A, Ozdemir I, Demirci E. Vaginal removal of prolapsed pedunculated submucosal myoma during pregnancy. Advances in Therapy 2007 July/August, vol 24 (4): 903-906.

3. De Vries M, Perquin D. Non-puerperal uterine inversion due to submucous myoma in a young woman: a case report. Journal of Medical Case Reports 2010, 4-21.

4. Golan A, Zachalka N, Lurie S, Sagiv R, Glezerman M. Vaginal removal of prolapsed pedunculated submucous myoma: a short, simple, and definitive procedure with minimal morbidity. Arch Gynecol Obstet. 2005 Jan; 271(1):11-3.

5. Hamid A, Balgobin S, Cherine A. Technique of vaginal myomectomy for intracavitary submucous myomas. Journal of Pelvic Medicine \& Surgery 2006 Nov / Dec, vol 12 (6): 339-341.

6. Hoffman M, Parsons A, Spellacy W. Expectant management of a prolapsing submucous uterine myoma. Journal of Gynecologic Surgery 2009 Jan, vol 16(2):29

7. Inab M, Hobeika E, Nassar A. A tale of 2 pedunculated myomas. American Journal of Obstet \& Gynec. 2005 Nov; vol 193(5): 1753-1755.

8. Jin K, Chang 1, Kyeong K, Cheol P. Spontaneous prolapse of pedunculated uterine submucosal leiomyoma: usefulness of broccoli sign on CT and MR imaging. Clinical Imaging 2008 May, vol 32 (3): 233-235.

9. Riley P. Treatment of prolapsed submucous fibroids. SA Medical Journal 1982 July, vol 62 (3):22-24. 